\title{
Job Satisfaction
}

\author{
Dr. P. K. Mishra \\ Principal, D.S.College, Gangtok, Sikkim, India
}

\begin{abstract}
Job satisfaction is one of the most crucial but controversial issues in industrial Psychology and behaviourial management in organization. It ultimately decides the extent of employ motivation through the development of organizational climate or environment satisfaction is specific subset of attitudes held by organizational members. It is the attitude one has towards his or her job. Stated another way, it is one's effective response to the job. Job satisfaction in a narrow sense means attitudes related to the job. It is concerned with such specific factors has wages, supervision, steadiness of employment, conditions of work, social relation of the job, prompt settlement of grievances, fair treatment of employer and other similar items. Job satisfaction is related to different Socio-economic and personal factors, such as: Age, Sex, Incentives, Working Environment, Education, duration of work etc. The present paper will highlight different factors affecting job satisfaction in pharmaceutical company in Sikkim, India.
\end{abstract}

Keywords: Job Satisfaction, Incentives, Skill, Social Security, Working Conditions.

\section{Introduction}

Job satisfaction is a general attitude which is the result of many specific attitude in three areas, namely (i) specific job factors; (ii) individual characteristics; and (iii) group relationship outside the job. These factors can never be isolated from each other for analysis. The approach which since to be opted is that job satisfaction is the favourableness or unfavourableness with which employees view their works. It results when job requirements suit to the wants and expectation of the employees.

However, a more comprehensive approach requires that many additional factors be included before a complete understanding of job satisfaction can be obtained. Such factors, such as ; the employee's age, health, temperament, desires and level of aspiration should be considered. Further, his family relationships, social status, recreational outlets, activity in organizational labour-political or purely social, contribute ultimately to the job satisfaction.

\section{Job Satisfaction and Behaviour}

Is there any relationship between how successfully an employee performs and the degree to which he is satisfied with the various aspects of his job? The answer to that question is not yet clearly established. Vroom (1964) has done an excellent job of examining the relationship between job satisfaction and various aspects of job behaviour. Vroom catagorised studies in terms of which job behaviours are correlated with job satisfaction. He groups them into studies of turnover, absenteeism, accident, and job performance. In summerising the research related to job satisfaction to job behaviour variables, Vroom draws a number of conclusion. Such as :

i. There is a constant negative relationship between job satisfaction and the probability of resignation.

ii. There is less consistant negative relationship between job satisfaction and abseentism.

iii. There is some indication of a negative relationship between job satisfaction and accidents.

iv. There is no single relationship between job satisfaction and job performance. Correlation between these variables vary within an extremely large range.

\section{Factors Relating to Job Satisfaction}

Job satisfaction is derived from many interrelated factors. Every factor has it's own importance and which can not be neglected. All these factors are subject to change from time to time and therefore study of these factors is important. These factors are:

\section{III.1. Personal Factors}

i. Sex : In most of the investigations on the subject, it is reveled that generally women are satisfied with their job than man. This may be because of multiple role of women when they take position outside home. It was found that, women prefer to work with friendly people, good social position in spite of less pay. 
ii. Age : Studies have found different results in different groups on the relationship of age with job satisfaction. Some feel that age has little relationship with job satisfaction but this relationship has importance in some job situations. In some groups job satisfaction is higher with increasing age in other groups it is lower.

iii. Education : In this relationship some studies show that there is a tendency for the more educated employees to be less satisfied and conversely the less educated employees to be more satisfied. But, other studies shows no relationship at all and certain variables such as ; companies advancement policy in relation to education have to be considered.

iv. Time of Job : Several studies show that job satisfaction is higher in first few days then falls slowly.

\section{III.2. FACTORS IN JOB}

i. Type of Work : The most important factor in the job is the type of job. Studies have shown that in job causes greater job satisfaction than the routine work. Other studies have shown that a majority of factory employees to be dissatisfied where as a minority of professionals were dissatisfied.

ii. Skill Required : Where skill exists to considerable degree, it tends to become the first source of satisfaction to the employees. Satisfaction in condition of work or in wages became prominent only where satisfaction in skill has materially decreased.

iii. Occupational Status : Occupational status shows a vary high correlation with intelligence, income and year of education. It has been found that employees are more dissatisfied in the jobs which have less social status and prestige.

iv. Responsibility : Responsibility also plays a major part in an industry. Thus studies on responsibility among factory managers have been found more significance leading them to job satisfaction.

\section{III.3 FACTORS CONTROLLED BY THE MANAGEMENT}

i. Wages : Wages are the most important factor of the job satisfaction. Higher the wages more the job satisfaction, but this is not necessarily lead to cover all employees satisfaction. Studies show that in some cases salary was rated well blow in job satisfaction, but security and opportunities for advancement by highly educated class of people is much higher than salary.

ii. Working Condition : Comfortable working conditions are ranked an important factor also. Better the working condition less will be fatigue and more will be job satisfaction.

iii. Benefits : Other benefits have been ramped as an important factor also. Since studies show that highly educated employees having a good pay give more importance to benefits and facilities.

iv. Security : All the studies show that employees want a steady work The higher will be the job satisfaction when there is a job security and vice -versa. But studies also show that security is also less important to better educated persons.

v. Opportunity for Promotion : Studies show that after years in the job people will give more importance to advancement than pay. Job satisfaction is more ebullient where there are ample opportunities for career advancement.

\section{Measuring Job Satisfaction}

There are many methods for measuring job satisfaction. By far, the most common method for collecting data regarding job satisfaction is the Likert scale (named after Rensis Likert). Other less common methods of for gauging job satisfaction include: Yes/No questions, True / False questions, point systems, checklists, and forced choice answers. This data is typically collected using an Enterprise Feedback Management (EFM) system.

The Job Descriptive Index (JDI), created by Smith, Kendall, \& Hulin (1969), is a specific questionnaire of job satisfaction that has been widely used. It measures one's satisfaction in five facets: pay, promotions and promotion opportunities, coworkers, supervision, and the work itself. The scale is simple, participants answer either yes, no, or can't decide (indicated by '?') in response to whether given statements accurately describe one's job.

The Job in General Index is an overall measurement of job satisfaction. It is an improvement to the Job Descriptive Index because the JDI focuses too much on individual facets and not enough on work satisfaction in general.

Other job satisfaction questionnaires include: the Minnesota Satisfaction Questionnaire (MSQ), the Job Satisfaction Survey (JSS), and the Faces Scale. The MSQ measures job satisfaction in 20 facets and has a long form with 100 questions (five items from each facet) and a short form with 20 questions (one item from each facet). The JSS is a 36 item questionnaire that measures nine facets of job satisfaction. Finally, the Faces Scale of job satisfaction, one of the first scales used widely, measured overall job satisfaction with just one item which participants respond to by choosing a face. 


\section{IV.1. Superior-Subordinate Communication}

Superior-subordinate communication is an important influence on job satisfaction in the workplace. The way in which subordinate's perceive a supervisor's behavior can positively or negatively influence job satisfaction. Communication behavior such as facial expression, eye contact, vocal expression, and body movement is crucial to the superior-subordinate relationship (Teven, $p$. 156). Nonverbal messages play a central role in interpersonal interactions with respect to impression formation, deception, attraction, social influence, and emotional expression (Burgoon, Buller, \& Woodall, 1996). Nonverbal immediacy from the supervisor helps to increase interpersonal involvement with their subordinates impacting job satisfaction. The manner in which supervisors communicate their subordinates may be more important than the verbal content (Teven, p. 156). Individuals who dislike and think negatively about their supervisor are less willing to communicate or have motivation to work where as individuals who like and think positively of their supervisor are more likely to communicate and are satisfied with their job and work environment. The relationship of a subordinate with their supervisor is a very important aspect in the workplace. Therefore, a supervisor who uses nonverbal immediacy, friendliness, and open communication lines is more willing to receive positive feedback and high job satisfaction from a subordinate where as a supervisor who is antisocial, unfriendly, and unwilling to communicate will naturally receive negative feedback and very low job satisfaction from their subordinate's in the workplace. Mood and emotions while working are the raw materials which cumulate to form the affective element of job satisfaction. (Weiss and Cropanzano, 1996). Moods tend to be longer lasting but often weaker states of uncertain origin, while emotions are often more intense, short-lived and have a clear object or cause. There is some evidence in the literature that state moods are related to overall job satisfaction. Positive and negative emotions were also found to be significantly related to overall job satisfaction. Frequency of experiencing net positive emotion will be a better predictor of overall job satisfaction than will intensity of positive emotion when it is experienced. Emotion regulation and emotion labor are also related to job satisfaction. Emotion work (or emotion management) refers to various efforts to manage emotional states and displays. Emotion regulation includes all of the conscious and unconscious efforts to increase, maintain, or decrease one or more components of an emotion. Although early studies of the consequences of emotional labor emphasized its harmful effects on workers, studies of workers in a variety of occupations suggest that the consequences of emotional labor are not uniformly negative.

It was found that suppression of unpleasant emotions decreases job satisfaction and the amplification of pleasant emotions increases job satisfaction. The understanding of how emotion regulation relates to job satisfaction concerns two models:

i) Emotional dissonance is a state of discrepancy between public displays of emotions and internal experiences of emotions, that often follows the process of emotion regulation. Emotional dissonance is associated with high emotional exhaustion, low organizational commitment, and low job satisfaction.

ii) Social interaction model. Taking the social interaction perspective, workers' emotion regulation might beget responses from others during interpersonal encounters that subsequently impact their own job satisfaction. For example: The accumulation of favorable responses to displays of pleasant emotions might positively affect job satisfaction performance of emotional labor that produces desired outcomes could increase job satisfaction.

\section{IV.2.Relationships and Practical Implications}

Job Satisfaction can be an important indicator of how employees feel about their jobs and a predictor of work behaviours such as organizational citizenship, absenteeism, and turnover. Further, job satisfaction can partially mediate the relationship of personality variables and deviant work behaviors.

One common research finding is that job satisfaction is correlated with life satisfaction. This correlation is reciprocal, meaning people who are satisfied with life tend to be satisfied with their job and people who are satisfied with their job tend to be satisfied with life. However, some research has found that job satisfaction is not significantly related to life satisfaction when other variables such as non work satisfaction and core self-evaluations are taken into account.

An important finding for organizations to note is that job satisfaction has a rather tenuous correlation to productivity on the job. This is a vital piece of information to researchers and businesses, as the idea that satisfaction and job performance are directly related to one another is often cited in the media and in some nonacademic management literature. A recent meta-analysis found an average uncorrected correlation between job satisfaction and productivity to be $\mathrm{r}=.18$; the average true correlation, corrected for research artifacts and unreliability, was $r=.30$. Further, the meta-analysis found that the relationship between satisfaction and performance can be moderated by job complexity, such that for high-complexity jobs the correlation between satisfaction and performance is higher $(\rho=.52)$ than for jobs of low to moderate complexity $(\rho=.29)$. In short, the relationship of satisfaction to productivity is not necessarily straightforward and can be influenced by a number 
of other work-related constructs, and the notion that "a happy worker is a productive worker" should not be the foundation of organizational decision-making.

With regard to job performance, employee personality may be more important than job satisfaction. The link between job satisfaction and performance is thought to be a spurious relationship; instead, both satisfaction and performance are the result of personality.

\section{Company Profile}

Cipla Ltd, is an innovative global pharmaceutical company that discovers, develops, manufactures and markets a broad range of healthcare products. The group's operations range from API to formulations, animal health products and cosmeceuticals. Headquartered in the city of Mumbai in India, the group has global operations in four continents spread across USA, Europe, Japan, Brazil, South Africa and 25 other emerging markets.

\section{V.1. Cipla Ltd, In Sikkim}

It was a challenging task to set up a new state-of-art formulation plant in just ELEVEN months but Cipla technical staff involved in Sikkim Plant did just that. On the $7^{\text {th }}$ of November 2006, Cipla Ltd, Plant was inaugurated at Rangpo in Sikkim. The plant spread over an area of 7500 sq.mt . The plant manufactures tablets and capsules for the domestic market. The various manufacturing operations at Sikkim Plant includes:

\section{V.2. Introduction Of HRM}

Human Resource Management (HRM) is the strategic and coherent approach to the management of the organization's most valuable assets - the people working there whom individually and collectively contribute to the achievement of the objectives of the business.

Human Resource Management (HRM) function includes a variety of activities and key among them is deciding what staffing needs we have and whether to use independent contractors or hire employees to fill their needs, recruitment and training the employees ensuring they are high performers, dealing with performance issues and ensuring their personnel and management practices conform to various regulation.

The goal of Human Resource Management is to help an organization to meet strategic goals by attracting and maintaining employees and to manage them effectively. The basic premise of the academic theory of HRM is that humans are not machines; therefore we need to have an interdisciplinary examination of people at the workplace. Fields such as psychology, industrial and organizational psychology, industrial relations, sociology and critical theories: post modernism, post - structuralism play major role. Many colleges and universities offer bachelor and master degrees in Human Resource Management.

There are a number of challenges in the Indian industry which require the serious attention of HR managers to 'find the right candidate' and build a 'conducive work environment' which will be beneficial for the employees, as well as the organization. A few of them are managing people, motivating work force, competency development, recruitment and training and the trust factor.

\section{Review of Literature}

One of the biggest preludes to the study of job satisfaction was the Hawthorne studies. These studies (1924-1933), primarily credited to Elton Mayo of the Harvard Business School, sought to find the effects of various conditions (most notably illumination) on workers' productivity. These studies ultimately showed that novel changes in work conditions temporarily increase productivity (called the Hawthorne Effect). It was later found that this increase resulted, not from the new conditions, but from the knowledge of being observed. This finding provided strong evidence that people work for purposes other than pay, which paved the way for researchers to investigate other factors in job satisfaction.

Scientific Management also had a significant impact on the study of job satisfaction. Frederick Winslow Taylor's 1911 book, 'Principles of Scientific Management', argued that there was a single best way to perform any given work task. This book contributed to a change in industrial production philosophies, causing a shift from skilled labor and piecework towards the more modern approach of assembly lines and hourly wages. The initial use of scientific management by industries greatly increased productivity because workers were forced to work at a faster pace. However, workers became exhausted and dissatisfied, thus leaving researchers with new questions to answer regarding job satisfaction. It should also be noted that the work of W.L. Bryan, Walter Dill Scott, and Hugo Munsterberg set the tone for Taylor's work.

Some argue that Maslow's hierarchy of needs theory, a motivation theory, laid the foundation for job satisfaction theory. This theory explains that people seek to satisfy five specific needs in life - physiological needs, safety needs, social needs, self-esteem needs, and self-actualization. This model served as a good basis from which early researchers could develop job satisfaction theories. 
Job satisfaction can also be seen within the broader context of the range of issues which affect an individual's experience of work, or their quality of working life. Job satisfaction can be understood in terms of its relationships with other key factors, such as general well-being, stress at work, control at work, home-work interface, and working conditions.

One of the most important aspects of an individual's work in a modern organization concerns the management of communication demands that he or she encounters on the job (Krayer, K. J., \& Westbrook, L., p. 85). Demands can be characterized as a communication load, which refers to "the rate and complexity of communication inputs an individual must process in a particular time frame (Faraca, Monge, \& Russel, 1977)." Individuals in an organization can experience communication over-load and communication under- load which can affect their level of job satisfaction. Communication overload can occur when "an individual receives too many messages in a short period of time which can result in unprocessed information or when an individual faces more complex messages that are more difficult to process (Farace, Monge, \& Russel, 1997)." Due to this process, "given an individual's style of work and motivation to complete a task, when more inputs exist than outputs, the individual perceives a condition of overload (Krayer, K. J., \& Westbrook, L., p. 86) which can be positively or negatively related to job satisfaction. In comparison, communication under load can occur when messages or inputs are sent below the individual's ability to process them (Farace, Monge, \& Russel, 1997)." According to the ideas of communication over-load and under-load, if an individual does not receive enough input on the job or is unsuccessful in processing these inputs, the individual is more likely to become dissatisfied, aggravated, and unhappy with their work which leads to a low level of job satisfaction.

\section{Methodology}

The present study was based on the following methodology.

\section{VII.1. OBJECTIVES OF THE STUDY}

The study was conducted in keeping the following objectives in mind:

a) To study the level of satisfaction of respondents towards working conditions and welfare facilities.

b) To study the level of satisfaction of respondents towards financial benefits, opportunities for promotion and training.

c) To study the opinion of respondents towards interpersonal relationship, appreciation of work and decision making.

d) To study the level of satisfaction of respondents towards standing rules, grievances readdressal system and disciplinary action, interest and boredom.

e) To find out over all level job satisfaction among the executives.

f) To give suggestions to improve the level of job satisfaction, if required.

\section{VII.2. DESIGN OF THE STUDY}

It is a Descriptive and Explorative study design, which had enabled to know the level of job satisfaction among the executives working at Cipla Sikkim,

\section{VII.3. SCOPE OF THE STUDY}

The scope of the study is limited to the Employees of the Cipla Sikkim.

\section{VII.4. OPERATIONAL DEFINITION} both the terms.

Job satisfaction consists of two words i.e. job and satisfaction. First of all, it is necessary to understand

a) Job : As per Webster Dictionary, Job means "A piece of work, specially an individual piece, work done in the routine of one's occupation or trade for a fixed price, anything one has to do, a duty, a responsibility, post of employment, an affair, matter of state of affairs, the process involved in accomplishment a task."

b) Satisfaction : As per the Webster Dictionary, satisfactions means " something that satisfies

(i) anything that brings pleasure and contentment,

(ii) settlement of debt, (iii) preparation of injury or insult - give gratification."

c) Job Satisfaction : Job satisfaction means," satisfaction with various aspects of the job and function."

d) Employee: He / She is an employee having the job of permanent / Temporary in nature in the affairs of the company."

\section{VII.5. SAMPLING}

A sample of 107 employees was taken which contributes to about $46 \%$ of the total employees. 
The result of the study was characterized on the basis of:

a) Total Respondent; and,

b) Departmental wise

\section{VII.6. TOOLS OF DATA COLLECTION}

Though the researcher has taken only employees of Cipla Sikkim and all of them are well educated, he had selected Structured Questionnaire Method for the Collection of data from the universe.

\section{VII.7. PILOT STUDY}

Before distributing questionnaire among the respondents, researcher first did his pilot study. He had distributed five questionnaires to five employees to know the response and also to know the lacunas. It was revealed from the filled in questionnaire that they were all set and clear. Then the questionnaire was finalized.

\section{VII.8. METHODS OF DATA COLLECTION}

Both primary and secondary methods were used for data collection. Primary means, the information which is given by the respondents through the questionnaire directly, and secondary method means, any source other than primary source, i.e. Office files, documents, Govt. Gazzetiers, Manuals etc.

\section{9. DATA ANALYSIS AND INTERPRETATION}

After all the data were displayed after tabulation the researcher had analysed the tabulated data as per the objectives of the study.

For the study, Average Satisfaction was calculated using the following formula:-

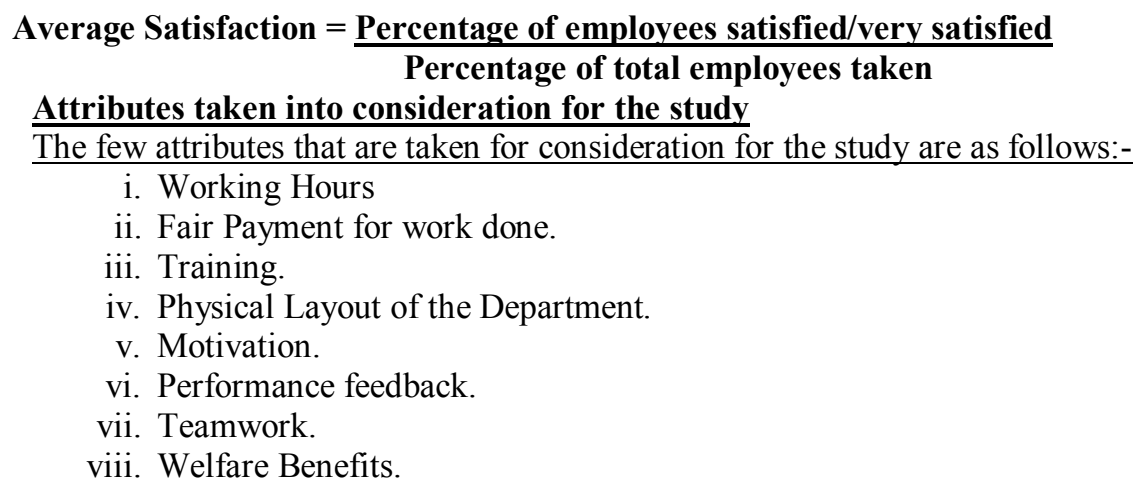

\section{Employee Satisfaction Measurement}

Employee satisfaction has been defined as a function of perceived performance and expectations. If the performance falls short of expectations, the employee is dissatisfied and if it matches the expectations, the employee is satisfied. The process is however, more complicated then it appears. It is more important for any organization to offer high satisfaction, as it reflects high loyalty and it will not lead to switching over once a better offer comes in.

\section{VIII.1.TOOLS FOR TRACKING AND MEASURING EMPLOYEE SATISFACTION}

i. Complaint and Suggestion System: Employee can freely deliver complaints and suggestions through facilities like suggestion box, personal meetings with seniors etc.

ii. Lost Employee Analysis: The exit interviews are conducted or employee loss rate is computed.

iii. Employee Satisfaction Survey: Periodic surveys by use of questionnaire or telephone calls to random sample of recent buyer help to find out employee satisfaction.

\section{VIII.2. SCALE CONSTRUCTION}

\section{VIII.2.1. For Questionnaire}

On the basis of different attributes taken into consideration, a questionnaire was prepared. To each, there are 4 possible answers out of which one is to be ticked. In case of pertaining to satisfaction, the respondent has to give a response in terms of very satisfied, satisfied, dissatisfied, very dissatisfied. 


\section{VIII.2.2. For interpretation}

After the collection of data, the results were plotted in the form of graph and the interpretation was carried out taking the following scale into consideration:

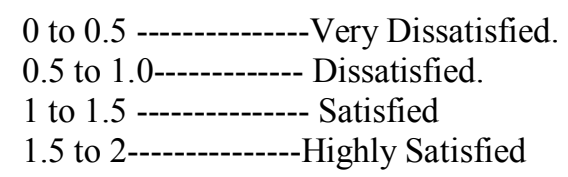

\section{Data Analysis And Interpretation}

Based on the data collected, as a whole, the total respondents are dissatisfied with the following attributes:
a. Working Hours
b. Training
c. Motivation, and
d. Team Work

and the employees are very much dissatisfied with

a) Performance feedback, and

b) Welfare Benefits

\section{Major Findings Of The Study}

On the basis of the methodology adopted for the study, the following findings were drawn:

\section{X.1. Satisfaction Level Of The Employees (Department Wise)}

In this organization, there are total six departments like Production, Quality Control and Assurance, Warehouse, Engineering, Finance and Human Resource Department. The researcher has tried to collect data from each of the department as the satisfaction level differs from one department to another.

\section{X.1.1. Production Department}

The percentage of employees taken into consideration is $45 \%$ of the total employees of the department.

The employees of Production department are highly satisfied with the physical condition of the department (1.9) and satisfied with payment structure (1.2); while very much dissatisfied with Performance Feedback (0.2), Team Work (0.2) \& Welfare Benefits (0.3); and dissatisfied with Working Hours (0.7), Training (0.5) and Motivation (0.5).

\section{X.1.2.Quality Control And Assurance Department}

This is one of the most important departments in any organization in general and pharmaceutical industry in particular. Thus, the employees of this department are almost satisfied and very much satisfied with all most all attributes except Performance Feedback (0.4), Team Work (0.4) and Welfare Benefits (0.8).

\section{X.1.3 WAREHOUSE DEPARTMENT}

The employees of this department are almost dissatisfied in all the factors and satisfied only with Working Hours and Training (1.2).

\section{X.1.4. ENGINEERING DEPARTMENT}

The employees of this engineering department are only satisfied with training (1) and very much satisfied with Physical Layout (1.6) and very much dissatisfied with Performance Feedback, Payment, Motivation \& Welfare Benefits (0.4), and dissatisfied in Team Work (0.8) and Working Hours (0.6).

\section{X.1.5. HUMAN RESOURCES and FINANCE DEPARTMENT}

As the total number of employees are less (Human Resources -3 and Finance Department-4) the researcher has collected from all of these seven employees.

The employees of both these departments are satisfied with Working Hours, Training, Physical Layout \& Team Work (1) and very much dissatisfied with Performance Feedback (0.5), Motivation \& Welfare Benefits (0.4), and dissatisfied with payment (0.7). 


\section{X.2.CAUSES FOR EMPLOYEE DISSATISFACTION} dissatisfaction

On the basis of data collection, the foregoing discussions would highlight the factors of Employees

\section{X.2.1 LONG WORKING HOURS}

The working hours generally starts from 8:30 am to 5:00 pm. However, mostly for reasons such as increase market demand employees need to work up to $7 \mathrm{pm}$ which may get extended up to $10 \mathrm{pm}$. The Long working hours when coupled with sleep disturbance cause detoriation of task performance because of its detrimental effect on things such as rate of errors, pace of work and social behavior and Long working hours also show an adverse effect on the health of the employees. Employees may face many problems related to health such as: a) mental health; and; b) cardiovascular problem. Furthermore, it also has a negative impact on the work-life balance and also disturbs the domestic relationships.

In the study, it was found that though majority of the respondent are satisfied with the payment structure, only certain percentage of employees in Warehouse, Engineering, Human Resources and Finance Department of Cipla Ltd, (Sikkim Plant) were of the view that they were not paid according to their contribution to the organization which is the most demotivating factor at the top.

\section{X.2.2.TRAINING}

Training has become extremely vital to the success of modern organizations. Organisation often compete on competencies- the core set of knowledge and expertise that give them an edge over competitors. Training plays a central role in nurturing and strengthening these competencies and in this way become part of the backbone of strategy implementation.

In addition, rapidly changing technologies require that employees continuously hone their knowledge, skills and abilities continuously to cope with new processes and systems. Many new employees come equipped with most of the KSA's needed to start work. Others may require extensive training before they are ready however to make their contribution to their organization. Almost all employees however need some type of training on the ongoing basis to maintain effective performance or to adjust to new work.

In the present study the following causes were found for employees' dissatisfaction related to imparting training to them.

a) These trainings are generally provided to the supervisory and managerial level employees which inhibits the junior level employees to increase their skill and knowledge to increase productivity.

ii) Employees are provided training only for their particular kind of job.

iii) In the Quality Control and Assurance Department. Employees lack proper theoretical knowledge of the chemicals that are used along with their properties which provides hindrance during their work.

\section{X.2.3.MOTIVATION}

After employees were hired and trained, it is important to motivate them to get desired efforts from them to achieve organizational objectives. Motivation factors are perceived needs of employee satisfaction of which contribute to employee performance and productivity. Motivation process starts with a physiological or psychological deficiencies or need that accelerates behavior or drive that is aimed at a goal or incentives.

The following conclusions were drawn relating to employees' dissatisfaction in relation to motivation.

Employees were generally demotivated as the management takes no step to identify employees' wants, the problem they face during their working in the organization. This reduces their feeling of being a part of the organization thereby reducing their efficiency at work.

\section{X.2.4.TEAMWORK}

Teamwork is a concept of people working together cooperatively as a team in order to accomplish the same goals or objectives. Applied to work place teamwork is a method that aligns employee mindset in a corporative and usually selfless manner, towards specific business purpose shared goals. Effective collaborative skills (knowledge) are necessary to work well in a team environment. As business and organizations are becoming larger and sophisticated, many employers attempt to enhance their employees' collaborative efforts through training, cross training and work-shops in order to help people effectively work together in a cohesive group.

On the basis of the findings the researcher had concluded the following reasons

i) Employees are generally concerned with accomplishment of individual goals rather than accomplishment of the goal of the team.

ii) Lack of good communication between the employees which inhibits effective teamwork 


\section{X.2.5. WELFARE BENEFITS}

Employee benefits constitute an indirect form of compensation intended to improve the quality of work life and personal life of the employees. Benefits represent $40 \%$ of the total payroll cost to the employer. In return, employers generally expect employees to be supportive to the organization and be more productive. Since employees have come to expect an increasing number of benefits, motivation values of these benefits depends on how the programme is designed and communicated.

In the study, it was found that the company follows 3 tier of benefits like, Officer Level, Managerial Level and worker level, which was the major reason for dissatisfaction among the employees.

\section{Conclusion And Recommendations}

Despite different policies and programmes by Government on Industrial Development, employees welfare and statutory norms employees of different industrial establishments are dissatisfied with the facilities provided to them by the management of the industrial establishment. The summary of the study on the basis of the objectives show the followings and recommend the management to take corrective measures for increasing productivity:

\section{XI.1. Working Hours}

Employees should be provided with relaxation period in between their working hours so that they can do their work more efficiently. Relaxation period should be scheduled as follows:

After working from 8:30 am to 10:00 am ---- Tea Break for 15 minutes.

After working from 10:15 am to 12:30 pm ---- Lunch Break for 30 minutes.

After working from 1:00 pm to 5:00 pm ---- Tea Break for 15 minutes.

When employees are working for extra hours:

After working from 5:15 pm to 7:00 pm ---- Tea Break for 15 minutes.

\section{XI.2. Payment Of Work Done}

a) The organization should come up with a clear cut method to ascertain the productivity of each and every employee and based on their performance, employees should be compensated with increments, rewards etc. This should be done in a transparent way and by mutually fixing the employee's KRA's and KPA's for future expectation and results.

b) The management should provide various rewarding schemes (both monetary and non- monetary) which would further increase the employees commitment towards the organization.

\section{XI.3. Training}

a) Organization should provide training facilities to junior level employees in order to enhance their knowledge and skills to increase productivity.

b) Employees should be provided with cross-functional training to provide employees with multiskills to take - up more responsibility.

c) Off-the-job training should be provided to the employees of the Quality Control and Assurance Department in order to provide them knowledge of the various chemicals that are to be used in their laboratory.

\section{XI.4 MOTIVATION}

a) A complain box should be kept in each department, so that employees can write down the problems related to their job and the management should continuously make a review of them and takes corrective measures accordingly.

b) The management should make an attempt to identify the social needs of the employees for which the manager should continuously interact with his team members.

\section{XI.5.TEAMWORK}

a) Management should take initiative to conduct seminars and workshops including group dynamic games to increase the teamwork of the organization.

b) Team members should conduct meetings ( both formal and informal) which would not only make the members aware of the team goal as well as to increase the communication between the team members

\section{XI.6 WELFARE BENEFITS}


The people who are concerned with the fooding are contractual employees. In order to enhance the quality; regular invigilation should be conducted by the contractual head. The HR personnel should also do a monthly invigilation so that the quality of food increases.

\section{References}

[1] Abraham, R. (1999). “The Impact Of Emotional Dissonance On Organizational Commitment And Intention To Turnover". Journal of Psychology, 133, p.p 441-455

[2] Ashforth, B. E., \& Humphrey, R. H. (1993). "Emotional Labor In Service Roles: The Influence Of Identity". Academy of Management Review, 18, p.p.88-115

[3] Bhogoliwal,T.N (1987); “ Personnel Management and Industrial Relations”, Agra, Sahitya Bhawan.

[4] Blum, M.L and Naylor,J.C; (1968), “Industrial Psychology - It's Theoretical and Social Foundations”, Newyork, Harper.

[5] Brief AP, Roberson L.(1989). "Job Attitude Organization: An Exploratory Study". Journal of Applied Social Psychology 19: p.p.717-727.

[6] Brief, 1998 cited in Weiss, H. M. (2002). "Deconstructing Job Satisfaction: Separating Evaluations, Beliefs And Affective Experiences". Human Resource Management Review, 12, p. 174

[7] Cote S.,Morgan LM (2002). "A Longitudinal Analysis Of The Association Between Emotion Regulation, Job Satisfaction, And Intentions To Quit". Journal of Organizational Behaviour;vol. 23, p.p. 947-962

[8] Cranny, Smith \& Stone, 1992 cited in Weiss, H. M. (2002). "Deconstructing Job Satisfaction: Separating Evaluations, Beliefs And Affective Experiences". Human Resource Management Review, 12, 173-194, p.174

[9] Finalay,W.W; Sartin,A.O; \& Tate,W.W; (1955), “Human Behaviour in Industry”, New York, Mc.Graw Hills.

[10] Fisher D. (2000)."Mood And Emotions While Working: Missing Pieces Of Job Satisfaction"? Journal of Organizational Behaviour ; 21, p.p. $185-202$

[11] Fried, Y., \& Ferris, G. R. (1987). "The validity of the Job Characteristics Model: A Review and Meta-analysis". Personnel Psychology, 40(2), p.p.287-322.

[12] Hackman, J. R., \& Oldham, G. R. (1976). "Motivation Through The Design Of Work: Test Of A Theory”. Organizational Behavior and Human Performance, 16, p.p. 250-279.

[13] Harrel,T.W.; (1964); “Industrial Psychology”; (Ind.ed); New-Delhi; O.U.P.

[14] Judge, T. A., Thoresen, C. J., Bono, J. E., \& Patton, G. K. (2001). "The Job Satisfaction-Job Performance Relationship: A Qualitative And Quantitative Review". Psychological Bulletin, 127(3), p.p.376-407.

[15] Locke, 1976 cited in Brief, A. P., \& Weiss, H. M. (2001). "Organizational Behavior: Affect In The Workplace". Annual Review of Psychology, 53, 279-307, p. 282

[16] Morris, J. A., \& Feldman, D. C. (1997). “Managing Emotions In The Workplace”. Journal of Managerial Issues, 9, p.p. $257-274$.

[17] Mount, M., Ilies, R., \& Johnson, E. (2006). "Relationship Of Personality Traits And Counterproductive Work Behaviors: The Mediating Effects Of Job Satisfaction". Personnel Psychology, 59, p.p.591-622. 